\title{
A STUDY ON THE PSYCHOMOTOR POTENTIAL OF PRIMARY SCHOOL STUDENTS FROM BACAU SPORTS HIGH SCHOOL
}

\author{
Șalgău Silviu1* \\ 1“"Vasile Alecsandri” University of Bacău, Calea Mărășești 157, 600115, România
}

Keywords: abilities, means, strategies, skills.

\begin{abstract}
In the process of physical training of the 1st-4th grade pupils, the improvement of psychomotor skills depends on certain available bodily reserves based on a hereditary background, but also on the abilities acquired during the body development and it can be influenced by the instructional-educational process. The main way for developing psychomotor skills in the $1^{\text {st }}$ to $4^{\text {th }}$ grades is represented by the activity organized during lessons in order to form motor abilities and skills, but using specific methods and means to determine the desired process. This paper presents specific means for developing psychomotor skills during the physical education lesson and it deals with their efficiency to know how to act, according to the resulted gains or losses, in such a way as to adopt in future activities, different contents, strategies and forms to determine an increase of the efficiency of the teaching process as a permanent improvement of the physical available resources and the motor level of the age of a young primary school student.
\end{abstract}

\section{Introduction}

Teaching physical education in the $1^{\text {st }}$ to $4^{\text {th }}$ grades has a significant role in terms of both its favourable influence on the process of body development and strengthening as well as a didactic instrument designed to encourage knowledge of children, their more rapid adaptation to the new educational requirements, integrating class groups and forming an active work climate based on understanding and mutual aid (Stan et al., 2001).

The physical education lesson is effective not only when it solves tasks of the moment in connection with movement learning, training and developing motor skills, performing exercises, but also when it makes a student understand the importance, usefulness and their need for developing his/her personality, in the general activity he/she will carry out (Raţă, 1999; Ardelean, 1993).

\section{Material and methods}

Hypotheses. In this study, we started from the following hypotheses:

*E-mail: salgausilviu@yahoo.com, tel. 0744165134 
- Developing the psychomotor potential is different for each of the four grades of the primary school, taking into account age characteristics and the ways of applying the means in order to obtain high indices to strengthen and develop motility in pupils;

- Measurement in standard conditions of a sample with a statistical significance may reveal the evolution of the motor essential parameters to determine the psychomotor potential of the primary school students.

Research subjects and operating conditions

The sample subject to research consisted of a number of 80 pupils in the $1^{\text {st }}-4^{\text {th }}$ grades at Bacau Sports High School.

Research was performed in the period from 1 October 2013 to 30 May 2014. As motor events we used the following: rounders ball throw, vertical expansion, speed running, skill complex, mobility, torso lift, torso extension, push-ups, support pull-ups, long-distance running and time endurance running (Loghin \& Stoicescu, 1992). These aimed at a model of the psychomotor potential of pupils from Bacau Sports High School.

\section{Results and discussions}

Recording the parameters and comparing their values collected two times during the school year 2013-2014, at relatively equal time intervals, offer unique information about the potential psychomotor level. A rhythmic registering of the realities, finding by comparison the tendencies of evolution, involution, or graphics of the ten motor parameters provide a synthesis on the determinant factors of growth and motor development of a batch of pupils promoted. From the summary of the values in the two semesters to investigate the potential schoolgirls and schoolboys, we used the calculation methodology for the psychomotor potential. We started from the idea that the psychomotor potential is a sum of all motor qualities.

It was necessary to use some connections in order to find out the degree of development for every motor quality and as well as for all together to be assessed by using the same measurement unit (Programe şcolare pentru învăţământul primar, 2010; Marinescu, 2000).

Therefore, we used the following calculation system: it is assumed that for the test of rounders ball throw, the best result in the $4^{\text {th }}$ grade was $60 \mathrm{~m}$, and the lowest, $10 \mathrm{~m}$, the mean being $20 \mathrm{~m}$. The differentiation between the subjects, if all had thrown the ball in the same fraction of a second, would start from the moment of its landing on the ground for the weakest throw $(10 \mathrm{~m})$, because up to this distance all competitors had been equal.

We can thus claim that for the respective pupils the $10 \mathrm{~m}$ distance is a stage threshold, indicating the beginning of some new relations between the competitors. The classroom mean is an expression of competition which takes place within the two extremities and cannot be assessed without taking into account the distance that separates it from this threshold and the distance between the mean and the best throw. 
According to this judgment, it is noted that the two illustrated values express the following realities of the rounders ball throw event:

- $60 \mathrm{~m}$ is the upper limit of the throw (the best value), which we noted with Ls;

- $20 \mathrm{~m}$ is the mean of the series of throws, which we noted with M;

- 60-10 represents the amplitude of the series of throw (absolute series amplitude), which we noted with $\mathrm{A}$, which shows the difference between the highest and the lowest performance;

- 20-10 shows the difference between the mean and the lowest limit of the series of data, respectively M-Ls, which we called it, conventionally elongation.

If we give the difference between the lowest and the highest performance a maximum of points, i.e. 100, then how much do we give for the difference between the classroom mean and the weakest value?

The following calculation can help us because: - if for Ls - Li $(50 \mathrm{~m}$, which is the quotient between $60-10 \mathrm{~m}$ ), we give 100 points, then, for the difference between $\mathrm{M}$ (the classroom mean) and $\mathrm{Li}$ (inferior limit) we will give 20 points, obtained from the fraction $\mathrm{x}=1000 / 50=20$, resulting from $50 \mathrm{x}=$ 1,000 points.

As such, the formula expressing the relationship is:

$\mathrm{X}=100(\mathrm{M}-\mathrm{Li}) /(\mathrm{Ls}-\mathrm{Li})$

We believe that the result faithfully reflects the classroom value only to the extent to which the mean characterizes the classroom correctly.

What is to be kept in mind is the fact that the smaller the denominator will be, namely the difference between the maximum performance of the class and the minimum (i.e. the amplitude) is lower, the higher the value of $\mathrm{X}$ characterizing the entire class will be.

In this case, the values which make up the sample will be grouped around the maximum performance. On the other hand, when the difference between the mean and the average value is low, it is clear that we will have to deal with a weaker group.

To facilitate the assessment of data resulting from the above formula, we attributed qualifications differentiated as follows:

- for those ranging between 100 - 80 points, the qualification is very well

- for those ranging between 79.9 - 60 points, the qualification is well

- for those ranging between 59.9 - 40 points, the qualification is satisfactory

- for those ranging between 39.9 - 20 points, the qualification is unsatisfactory

- for those ranging between 19.9 - 0 points, the qualification is weak.

It may happen that the mean of a sample for any event, to be weaker than the mean of another sample, but due to the fact that the first has extreme values that are closer to the mean, the assessment in points can still be better.

If we imagined that in a class the vast majority of the results are grouped towards the lower limit, and a few of them were quite exceptional, the latter would increase the classroom mean. However, this mean cannot convince us 
that we are dealing with a class with good motility, but that the mean was in fact drawn or increased by those few remarkable performances. To be able to make a consistent assessment, we took as reference data the upper and lower limits in the second assessment, the scores on each of the two tests being calculated accordingly.

As a safety measure to eliminate abnormal results, a percentage of $1 \%$ was removed from the data obtained. Based on this calculation methodology data were processed data which resulted in scores on classes and events, ranging between 20 - 50 points, falling within the previously-mentioned conventional qualifications.

By comparing the means of the motor values of the two consecutive tests, respectively tables 1 and 2, we can see that those from the first test are one to two points higher than those from the second test.

Comparative analysis of the results obtained in the $1^{\text {st }}-4^{\text {th }}$ grades

Table 1. Score of the motor events in schoolgirls on grades

\begin{tabular}{|c|c|c|c|}
\hline Grade & Event & Test I & Test II \\
\hline \multirow[t]{12}{*}{$1^{\text {st }}$} & Rounders ball throw & 35.66 & 32.58 \\
\hline & Vertical expansion & 34.50 & 33.87 \\
\hline & Speed running & 40.32 & 40.32 \\
\hline & Skill complex & 15.28 & 24.23 \\
\hline & Mobility & 56.89 & 58.30 \\
\hline & Torso lift & 19.68 & 19.20 \\
\hline & Torso extension & 24.60 & 24.44 \\
\hline & Push-ups & 14.80 & 20.00 \\
\hline & Support pull-ups & 13.70 & 15.00 \\
\hline & Long-distance running & 25.25 & 17.88 \\
\hline & Time endurance running & 21.85 & 14.18 \\
\hline & Mean for motor values & 27.61 & 27.27 \\
\hline \multirow[t]{12}{*}{$2^{\text {nd }}$} & Rounders ball throw & 41.47 & 37.78 \\
\hline & Vertical expansion & 45.76 & 41.30 \\
\hline & Speed running & 42.30 & 39.51 \\
\hline & Skill complex & 29.84 & 37.17 \\
\hline & Mobility & 52.86 & 53.63 \\
\hline & Torso lift & 27.78 & 20.63 \\
\hline & Torso extension & 29.27 & 28.89 \\
\hline & Push-ups & 18.17 & 20.00 \\
\hline & Support pull-ups & 15.30 & 15.00 \\
\hline & Long-distance running & 21.40 & 10.07 \\
\hline & Time endurance running & 18.30 & 8.50 \\
\hline & Mean for motor values & 31.14 & 28.41 \\
\hline \multirow[t]{3}{*}{$3^{\text {rd }}$} & Rounders ball throw & 42.63 & 35.77 \\
\hline & Vertical expansion & 44.48 & 40.37 \\
\hline & Speed running & 52.36 & 53.06 \\
\hline
\end{tabular}




\begin{tabular}{|l|l|l|l|}
\hline \multirow{6}{*}{} & Skill complex & 37.29 & 41.08 \\
\cline { 2 - 4 } & Mobility & 52.97 & 52.42 \\
\cline { 2 - 4 } & Torso lift & 29.91 & 29.82 \\
\cline { 2 - 4 } & Torso extension & 31.61 & 34.09 \\
\cline { 2 - 4 } & Push-ups & 20.40 & 22.85 \\
\cline { 2 - 4 } & Support pull-ups & 17.10 & 17.50 \\
\cline { 2 - 4 } & Long-distance running & 26.21 & 15.13 \\
\cline { 2 - 4 } & Time endurance running & 22.27 & 12.57 \\
\cline { 2 - 4 } & Mean for motor values & 34.21 & 32.24 \\
\hline $4^{\text {th }}$ & Rounders ball throw & 46.09 & 38.71 \\
\cline { 2 - 4 } & Vertical expansion & 46.06 & 38.37 \\
\cline { 2 - 4 } & Speed running & 27.64 & 23.84 \\
\cline { 2 - 4 } & Skill complex & 43.98 & 43.98 \\
\cline { 2 - 4 } & Mobility & 60.86 & 60.84 \\
\cline { 2 - 4 } & Torso lift & 31.47 & 26.35 \\
\cline { 2 - 4 } & Torso extension & 35.26 & 35.55 \\
\cline { 2 - 4 } & Push-ups & 20.78 & 24.24 \\
\cline { 2 - 4 } & Support pull-ups & 17.65 & 17.50 \\
\cline { 2 - 4 } & Long-distance running & 23.35 & 25.36 \\
\cline { 2 - 4 } & Time endurance running & 26.22 & 14.84 \\
\cline { 2 - 4 } & Mean for motor values & 34.49 & 31.83 \\
\hline \multirow{2}{*}{} & & \\
\hline
\end{tabular}

Table 2. Score of the motor events in schoolboys on grades

\begin{tabular}{|c|l|l|l|}
\hline Grade & Event & Test I & Test II \\
\hline $1^{\text {st }}$ & Rounders ball throw & 41.85 & 34.97 \\
\cline { 2 - 4 } & Vertical expansion & 43.63 & 42.18 \\
\cline { 2 - 4 } & Speed running & 37.07 & 41.63 \\
\cline { 2 - 4 } & Skill complex & 40.89 & 38.20 \\
\cline { 2 - 4 } & Mobility & 54.89 & 54.78 \\
\cline { 2 - 4 } & Torso lift & 21.14 & 20.17 \\
\cline { 2 - 4 } & Torso extension & 25.26 & 24.44 \\
\cline { 2 - 4 } & Push-ups & 18.60 & 23.33 \\
\cline { 2 - 4 } & Support pull-ups & 18.40 & 20.00 \\
\cline { 2 - 4 } & Long-distance running & 22.54 & 16.60 \\
\cline { 2 - 4 } & Time endurance running & 18.79 & 13.34 \\
\cline { 2 - 4 } & Mean for motor values & 31.19 & 29.97 \\
\hline $2^{\text {nd }}$ & Rounders ball throw & 41.85 & 34.97 \\
\cline { 2 - 4 } & Vertical expansion & 47.38 & 43.00 \\
\cline { 2 - 4 } & Speed running & 41.28 & 36.36 \\
\cline { 2 - 4 } & Skill complex & 35.45 & 39.68 \\
\cline { 2 - 4 } & Mobility & 45.89 & 46.42 \\
\cline { 2 - 4 } & Torso lift & 22.32 & 19.86 \\
\cline { 2 - 4 } & Torso extension & 30.67 & 31.11 \\
\cline { 2 - 4 } & Push-ups & 20.00 & 22.85 \\
\cline { 2 - 4 } & Support pull-ups & 23.40 & 20.00 \\
\hline
\end{tabular}




\begin{tabular}{|c|c|c|c|}
\hline & Long-distance running & 24.83 & 11.74 \\
\hline & Time endurance running & 24.12 & 16.64 \\
\hline & Mean for motor values & 32.48 & 29.33 \\
\hline $3^{\text {rd }}$ & Rounders ball throw & 62.26 & 48.26 \\
\hline & Vertical expansion & 52.71 & 46.78 \\
\hline & Speed running & 53.59 & 54.24 \\
\hline & Skill complex & 42.32 & 45.50 \\
\hline & Mobility & 54.87 & 55.16 \\
\hline & Torso lift & 25.87 & 24.37 \\
\hline & Torso extension & 35.90 & 36.36 \\
\hline & Push-ups & 25.75 & 22.27 \\
\hline & Support pull-ups & 22.00 & 23.07 \\
\hline & Long-distance running & 14.52 & 18.22 \\
\hline & Time endurance running & 32.82 & 18.44 \\
\hline & Mean for motor values & 38.42 & 35.78 \\
\hline $4^{\text {th }}$ & Rounders ball throw & 64.32 & 48.72 \\
\hline & Vertical expansion & 49.62 & 40.92 \\
\hline & Speed running & 36.04 & 30.62 \\
\hline & Skill complex & 47.88 & 45.14 \\
\hline & Mobility & 53.93 & 53.43 \\
\hline & Torso lift & 23.04 & 18.78 \\
\hline & Torso extension & 40.00 & 37.78 \\
\hline & Push-ups & 26.11 & 25.21 \\
\hline & Support pull-ups & 26.25 & 25.00 \\
\hline & Long-distance running & 28.68 & 16.75 \\
\hline & Time endurance running & 29.04 & 17.05 \\
\hline & Mean for motor values & 38.63 & 32.72 \\
\hline
\end{tabular}

Recording the parameters and calculating the means are useful for research because they ensure the values of the psychosomatic parameters which shall be compared over time, as a result of the periodic research. To be more precise, for the representation to be more obvious, we used the graphical method to emphasize the media of the motor value.

Moving the analysis in the psychosomatic area (tables 1 and 2), we can see that the means reported on the second test are better than on the first. As it was expected, at the age of primary school (6-10 years), the psychosomatic values in schoolgirls are smaller than in schoolboys. It must be noted that the psychosomatic means, both for schoolgirls and schoolboys are labelled as satisfactory and unsatisfactory.

The tables analysis shows that in a classroom the vast majority of the results are grouped towards the lower limit, and a few of them would be quite exceptional, the latter would increase the classroom mean. However, this mean cannot convince that we are dealing with a class with good motility, but, in fact, the mean was drawn or increased by those few remarkable performances. 


\section{Conclusions}

1. The improvement of motor capacity in physical training is aimed at refining the level of motor skill development in primary school students.

2. Based on the development of the psychomotor potential of primary school students within Bacau Sports High School there must be developed the idea to form the self-overtaking in practising and structuring exercises specific to motor quality strengthening.

3. The measurement in standard conditions of a sample with statistical significance should highlight the evolution of essential motor parameters, taking into account the development of the primary school students' psychomotor potential.

4. Reaching a harmonious physical development can be achieved through a wide range of exercises, taken from different sports disciplines and adapted to the requirements of a physical education lesson for the purpose of diversifying psychomotor potential.

5. Receptiveness to new and creative combination of the means and methods used in developing the psychomotor potential in primary school students lead directly to a good optimization of a lesson.

6. For primary school education, for each of the capacities and competencies assessed, a teacher will use variants referred to as optional events.

7. In developing the psychomotor potential in primary school students, small or average circuit will be used.

8. Harmonious development of the loco-motor system, as well as of the other body systems and apparatuses and in particular circulation and breathing, must constitute the condition of a multilateral manifestation of the body capacity, for training and improving motor skills and abilities, for developing psychomotor aptitudes in primary school students.

9. Together with reaching the psychomotor indices at the end of primary school education, the organization of the instructional-educational process must have in view to maximize the physical exercise influences in order to train and develop personality features and traits.

10. It is necessary that the physical education classes in primary schools should contain means leading to forming a psychomotor potential in accordance with the requirements of the improvement process of physical development in accordance with specific requirements of the educational curricula.

\section{References}

1. ARDELEAN, T. (1993). Calităţi motrice de bază, București: Edit. Didactică și Pedagogică;

2. LOGHIN, M, STOICESCU, A. (1992). Îndrumar metodic - educație fizică, clasele I-IV, București: Edit. Didactică și pedagogică;

3. MARINESCU, I. T. (2000). Metodica predării educaţiei fizice la grădiniţă şi la clasele I - IV), Iaşi: Edit. AS'S;

4. RAŢĂ, G. (1999). Aptitudini motrice de bază), Bacău: Edit. Plumb; 
5. Programe şcolare pentru învăţământul primar. (2010). București: Edit. Corint;

6. STAN, L. et al. (2001). Educaţie fizică - ghid metodologic privind proiectarea activitătilor de predare - invăţare - evaluare la clasele I - IV), București: Edit. Aramis.

\title{
STUDIU PRIVIND POTENȚIALUL PSIHOMOTRIC AL ELEVILOR DIN CICLUL PRIMAR DE LA NIVELUL LICEULUI SPORTIV BACĂU
}

\author{
Şalgău Silviu ${ }^{1}$ \\ ${ }^{1}$ Universitatea “Vasile Alecsandri” din Bacău, Calea Mărășești 157, 600115, România
}

Cuvinte cheie: deprinderi, mijloace, strategii, aptitudini.

\section{Rezumat}

În procesul de pregătire fizică la elevii claselor I-IV, dezvoltarea aptitudinilor psihomotrice depind de anumite disponibilităţi ale organismului bazate pe un fond ereditar, dar şi de însuşirile dobândite pe parcursul dezvoltării organismului, poate fi influenţată prin procesul instructiv-educativ. Calea principală pentru dezvoltarea aptitudinilor psihomotrice la clasele I-IV o constituie activitatea organizată în cadrul lecţiilor în scopul formării priceperilor şi deprinderilor motrice, însă utilizându-se metode şi mijloace specifice pentru a determina procesul dorit. Lucrarea prezintă mijloacele specifice pentru dezvoltarea aptitudinilor psihomotrice în lecţia de educaţie fizică, şi urmăreşte eficienţa lor pentru a şti în ce mod să se acţioneze, în funcţie de plusurile sau minusurile obţinute, astfel încât să se adopte în activitatea viitoare, conţinuturi, strategii şi forme diferenţiate care să determine creşterea eficienţei procesului didactic ca o perfecţionare permanentă a disponibilităţilor fizice şi a nivelului motric al vârstei şcolarului mic.

\section{Introducere}

Predarea educaţiei fizice la clasele I-IV are un rol însemnat atât în ceea ce priveşte influenţa ei favorabilă asupra procesului de dezvoltare şi fortificare a organismului cât şi ca instrument didactic menit să favorizeze cunoaşterea copiilor, adaptarea lor mai rapidă la noile cerinţe şcolare, integrarea colectivelor claselor şi formarea unui climat activ de muncă, de bună înţelegere şi întrajutorare (Stan et al., 2001).

Lecţia de educaţie fizică este eficientă nu numai atunci când rezolvă sarcini de moment în legătură cu însuşirea mişcării, formarea şi dezvoltarea deprinderilor motrice, efectuarea exerciţiilor, ci şi când îl face pe elev să înţeleagă importanţa, utilitatea şi necesitatea acestora în dezvoltarea personalităţii sale, în activitatea generală pe care o desfăşoară şi o va desfăşura (Raţă, 1999; Ardelean, 1993). 


\section{Material şi metode}

Ipotezele lucrării. În cadrul lucrării s-a pornit de la următoarele ipoteze:

- Dezvoltarea fizică armonioasă este diferită pe cei patru ani şi există puseuri de creştere evidente. Dovada este furnizată de rezultatele obţinute de elevii claselor studiate.

- Măsurarea în condiții standard a unui eșantion cu o semnificație statistică, poate să evidențieze evoluția parametrilor antropometrici și motrici esențiali pentru determinarea potentialului biomotric al elevilor din ciclul primar.

Subiecţii cercetării. Lotul supus studiului a cuprins un număr de 80 elevi de clasele a I-a - a IV-a de la Liceul cu program spotiv - Bacău.

Desfășurarea cercetării. Cercetarea s-a realizat în perioada 1 octombrie 2013 şi 30 mai 2014. Ca probe motrice s-au folosit următoarele: aruncare minge oină, detentă verticală, alergare viteză, complex îndemânare, mobilitate, ridicare trunchi, extensie trunchi, flotări, tracțiuni cu sprijin, alergare rezistență-distanță şi alergare rezistență-timp (Loghin \& Stoicescu, 1992).

Toate acestea având drept scop un model al potenţialului psihomotric a elevilor din Liceul cu program sportiv din Bacău.

\section{Rezultate şi discuţii}

Înregistrarea parametrilor și compararea valorilor lor, culese de două ori pe parcursul anului școlar 2013-2014, la intervale relativ egale de timp, oferă o informație unică despre nivelul potențialului psihomotric. Consemnarea ritmică a realităților, constatarea prin comparație a tendințelor de evoluție, involuție, sau a graficelor celor zece parametri motrici, oferă o sinteză revelatoare asupra factorilor determinanți privind creșterea și dezvoltarea motrică a unor promoții de elevi. Din sinteza valorilor celor două semestre de cercetare a potențialului elevilor și elevelor, s-a folosit metodologia de calcul mai veche privind potențialul psihomotric. Atunci s-a plecat de la ideea valabilă și astăzi, că acesta rezultă din însumarea tuturor calităților motrice.

Întrebarea pusă a fost următoarea: dacă mediile acestor calități valorează fiecare, în mod invariabil, 50 puncte, nu înseamnă oare că eșantioanele, respectiv clasele de elevi, sunt egale din punct de vedere al rezistenței (50 pct.) la fel de puternici, probele de forță (50 de puncte), asemănător pentru cei îndemânatici (50 de puncte) etc.?

Practic, acest lucru este imposibil. Ca atare, s-a impus folosirea altor relații pentru a cunoaște gradul de dezvoltare al fiecărei calități motrice în parte și al tuturor împreună, în scopul aprecierii lor prin aceași unitate de măsură (Programe şcolare pentru învățământul primar, 2010; Marinescu, 2000).

În consecință, s-a folosit următorul sistem de calcul: se presupune că la proba de aruncare a mingii de oină, cel mai bun rezultat din clasa a IV-a a fost $60 \mathrm{~m}$, iar cel mai slab, $10 \mathrm{~m}$, media ei fiind de $20 \mathrm{~m}$. Diferențierea dintre subiecți, în cazul în care toți ar fi aruncat mingea în aceeași fracțiune de secundă, începe din momentul căderii pe sol a celei mai slabe dintre aruncări (10 m), pentru că până la această distanță toți competitorii au fost egali între ei. Se 
poate, deci, afirma că pentru elevii respectivi distanța de $10 \mathrm{~m}$ este un prag al eșalonării, care semnalizează începutul unor noi relații între competitori. Media însăşi a clasei, care nu este altceva decât o expresie a întrecerii ce se desfăşoară între hotarele celor două extremități, nu poate să fie apreciată fără să se țină seama de distanța care o desparte de acest prag, ca și de distanța dintre ea și aruncarea ce mai bună.

Pe fondul acestei judecăți, se apreciază că cele două valori exemplificate exprimă următoarele realități ale probei de aruncare a mingii de oină:

- 60 m este limita superioară a aruncării (ce mai bună valoare), pe care o notăm cu Ls

- 20 m este media șirului de aruncări pe clasă, pe care o notăm cu M

- 60-10 reprezintă amplitudinea şirului (amplitudinea absolută a seriei) de aruncări, pe care o notăm cu A, care indică diferența dintre cea mai mare performanță și cea mi mică.

- 20-10 arată diferența dintre media și limita inferioară a șirului de date, respectiv M-Ls, pe care am numit-o convențional eleongaţie.

Acordând diferenței dintre cea mai joasă și ce amia înaltă performanță maximum de puncte, adică 100 , atunci diferenței dintre media clasei și ce mai slabă valoare, cât îi oferim?

Calculul ne ajută întrucât: dacă pentru Ls - Li (50 m, care este câtul dintre 60-10 m), acordăm 100 de puncte, atunci, pentru diferența dintre M (media clasei) și Li (limita inferioară) vom oferi 20 puncte, obţinute din fracția x = $1000 / 50=20$, rezultată din faptul că 50x $=1000$ pct.

Ca atare, formula care exprimă această relație este: X = 100(M-Li)/(Ls-Li)

Considerăm că rezultatul oglindește cu fidelitate valoarea clasei numai în măsura în care însăși media caracterizează clasa într-un mod corect.

De reținut este faptul că, cu cât numitorul va fí mai mic, adică diferența dintre performanța maximă a clasei și cea minimă (respectiv amplitudinea) este mai mică, cu atât valoarea lui X, care caracterizează întreaga clasă va fi mai mare.

În acest caz, valorile ce compun eșantionul în cauză vor fi grupate în jurul performanței maxime. În schimb, când diferența dintre medie și valoarea medie este mică, este clar că vom avea de-a face cu o colectivitate mai slabă.

Pentru ușurarea evaluării datelor rezultate din formula de mai sus, să acordăm calificative diferențiate astfel:

- pentru cele cuprinse între 100-80 pct, calificativul foarte bine

- pentru cele cuprinse între 79,9-60 pct, calificativul bine

- pentru cele cuprinse între 59,9-40 pct, calificativul satisfăcător

- pentru cele cuprinse între 39,9-20 pct, calificativul nesatisfăcător

- pentru cele cuprinse între 19,9-0 pct, calificativul slab.

Se poate întâmpla ca media unui eșantion la o probă oarecare, să fie mai slabă decât media altui eșantion, dar pentru că primul are valori extreme mai apropiate de medie, aprecierea în puncte poate să fie totuşi mai bună.

Dacă ne-am imagina că într-o clasă marea majoritate a rezultatelor sunt grupate către limita inferioară, iar câteva dintre acestea ar fi cu totul excepționale, 
cele din urmă ar face să crească media clasei respective. Dar această medie nu ne poate convinde că avem de-a face cu o clasă cu o bună motricitate, ci că de fapt media a fost trasă sau urcată de cele câteva performanțe remarcabile.

Pentru a putea realiza o apreciere unitară, au fost luate ca date de referință limitele inferioară și superioară de la testarea a doua, punctajele la fiecare dintre cele două testări fiind calculate în functie de acestea.

Ca măsură de siguranță păentru eliminarea rezultatelor aberante, din datele recoltate a fost eliminat un procent de $1 \%$.

Pe temeiul acestei metodologii de calcul s-au prelucrat datele, din care au rezultat punctaje pe clase și pe probe, cuprinse în cea mai mare parte între 20-50 puncte, care se încadrează în calificativele convenționale amintite.

Comparând mediile valorilor motrice ale celor două testări consecutive, respectiv tabelele 1,2 , constatăm că cele din prima testare sunt cu unul până la două puncte mai mari decât cele din a doua testare.

Analiza comparativă a rezultatelor obținute la clasa I-a - a IV-a

Tabelul 1. Punctajul probelor motrice ale fetelor pe clase

\begin{tabular}{|l|l|l|l|}
\hline Clasa & Proba & Testarea I & Testarea II \\
\hline I-a & Arunc. minge oină & 35,66 & 32,58 \\
\cline { 2 - 4 } & Detentă verticală & 34,50 & 33,87 \\
\cline { 2 - 4 } & Alergare viteză & 40,32 & 40,32 \\
\cline { 2 - 4 } & Complex îndemânare & 15,28 & 24,23 \\
\cline { 2 - 4 } & Mobilitate & 56,89 & 58,30 \\
\cline { 2 - 4 } & Ridicare trunchi & 19,68 & 19,20 \\
\cline { 2 - 4 } & Extensie trunchi & 24,60 & 24,44 \\
\cline { 2 - 4 } & Flotări & 14,80 & 20,00 \\
\cline { 2 - 4 } & Tracțiuni cu sprijin & 13,70 & 15,00 \\
\cline { 2 - 4 } & Alerg. rezist-dist. & 25,25 & 17,88 \\
\cline { 2 - 4 } & Alerg. rezist.-timp & 21,85 & 14,18 \\
\cline { 2 - 4 } & Media val. motrice & 27,61 & 27,27 \\
\hline a II-a & Arunc. minge oină & 41,47 & 37,78 \\
\cline { 2 - 4 } & Detentă verticală & 45,76 & 41,30 \\
\cline { 2 - 4 } & Alergare viteză & 42,30 & 39,51 \\
\cline { 2 - 4 } & Complex îndemânare & 29,84 & 37,17 \\
\cline { 2 - 4 } & Mobilitate & 52,86 & 53,63 \\
\cline { 2 - 4 } & Ridicare trunchi & 27,78 & 20,63 \\
\cline { 2 - 4 } & Extensie trunchi & 29,27 & 28,89 \\
\cline { 2 - 4 } & Flotări & 18,17 & 20,00 \\
\cline { 2 - 4 } & Tracțiuni cu sprijin & 15,30 & 15,00 \\
\cline { 2 - 4 } & Alerg. rezist-dist. & 21,40 & 10,07 \\
\cline { 2 - 4 } & Alerg. rezist.-timp & 18,30 & 8,50 \\
\cline { 2 - 4 } & Media val. motrice & 31,14 & 28,41 \\
\hline a III-a & Arunc. minge oină & 42,63 & 35,77 \\
\hline
\end{tabular}




\begin{tabular}{|l|l|l|l|}
\hline \multirow{7}{*}{} & Detentă verticală & 44,48 & 40,37 \\
\cline { 2 - 4 } & Alergare viteză & 52,36 & 53,06 \\
\cline { 2 - 4 } & Complex îndemânare & 37,29 & 41,08 \\
\cline { 2 - 4 } & Mobilitate & 52,97 & 52,42 \\
\cline { 2 - 4 } & Ridicare trunchi & 29,91 & 29,82 \\
\cline { 2 - 4 } & Extensie trunchi & 31,61 & 34,09 \\
\cline { 2 - 4 } & Flotări & 20,40 & 22,85 \\
\cline { 2 - 4 } & Tractiuni & 17,10 & 17,50 \\
\cline { 2 - 4 } & Alerg. rezist-dist. & 26,21 & 15,13 \\
\cline { 2 - 4 } & Alerg. rezist.-timp & 22,27 & 12,57 \\
\hline \multirow{7}{*}{ IV-a } & Media val. motrice & 34,21 & 32,24 \\
\cline { 2 - 4 } & Arunc. minge oină & 46,09 & 38,71 \\
\cline { 2 - 4 } & Detentă verticală & 46,06 & 38,37 \\
\cline { 2 - 4 } & Alergare viteză & 27,64 & 23,84 \\
\cline { 2 - 4 } & Complex îndemânare & 43,98 & 43,98 \\
\cline { 2 - 4 } & Mobilitate & 60,86 & 60,84 \\
\cline { 2 - 4 } & Ridicare trunchi & 31,47 & 26,35 \\
\cline { 2 - 4 } & Extensie trunchi & 35,26 & 35,55 \\
\cline { 2 - 4 } & Flotări & 20,78 & 24,24 \\
\cline { 2 - 4 } & Tracțiuni & 17,65 & 23,50 \\
\cline { 2 - 4 } & Alerg. rezist-dist. & 26,22 & 14,84 \\
\hline & Alerg. rezist.-timp & & 31,83 \\
\cline { 2 - 4 } & Media val. motrice & \\
\hline
\end{tabular}

Tabelul 2. Punctajul probelor motrice ale băieților pe clase

\begin{tabular}{|l|l|l|l|}
\hline Clasa & Proba & Testarea I & Testarea II \\
\hline \multirow{4}{*}{ I-a } & Arunc. minge oină & 41,85 & 34,97 \\
\cline { 2 - 4 } & Detentă verticală & 43,63 & 42,18 \\
\cline { 2 - 4 } & Alergare viteză & 37,07 & 41,63 \\
\cline { 2 - 4 } & Complex îndemânare & 40,89 & 38,20 \\
\cline { 2 - 4 } & Mobilitate & 54,89 & 54,78 \\
\cline { 2 - 4 } & Ridicare trunchi & 21,14 & 20,17 \\
\cline { 2 - 4 } & Extensie trunchi & 25,26 & 24,44 \\
\cline { 2 - 4 } & Flotări & 18,60 & 23,33 \\
\cline { 2 - 4 } & Tracțiuni cu sprijin & 18,40 & 20,00 \\
\cline { 2 - 4 } & Alerg. rezist-dist. & 22,54 & 16,60 \\
\cline { 2 - 4 } & Alerg. rezist.-timp & 18,79 & 13,34 \\
\cline { 2 - 4 } & Media val. motrice & 31,19 & 29,97 \\
\hline \multirow{5}{*}{ II-a } & Arunc. minge oină & 41,85 & 34,97 \\
\cline { 2 - 4 } & Detentă verticală & 47,38 & 43,00 \\
\cline { 2 - 4 } & Alergare viteză & 41,28 & 36,36 \\
\cline { 2 - 4 } & Complex îndemânare & 35,45 & 39,68 \\
\cline { 2 - 4 } & Mobilitate & 45,89 & 46,42 \\
\cline { 2 - 4 } & Ridicare trunchi & 22,32 & 19,86 \\
\cline { 2 - 4 } & Extensie trunchi & 30,67 & 31,11 \\
\hline
\end{tabular}




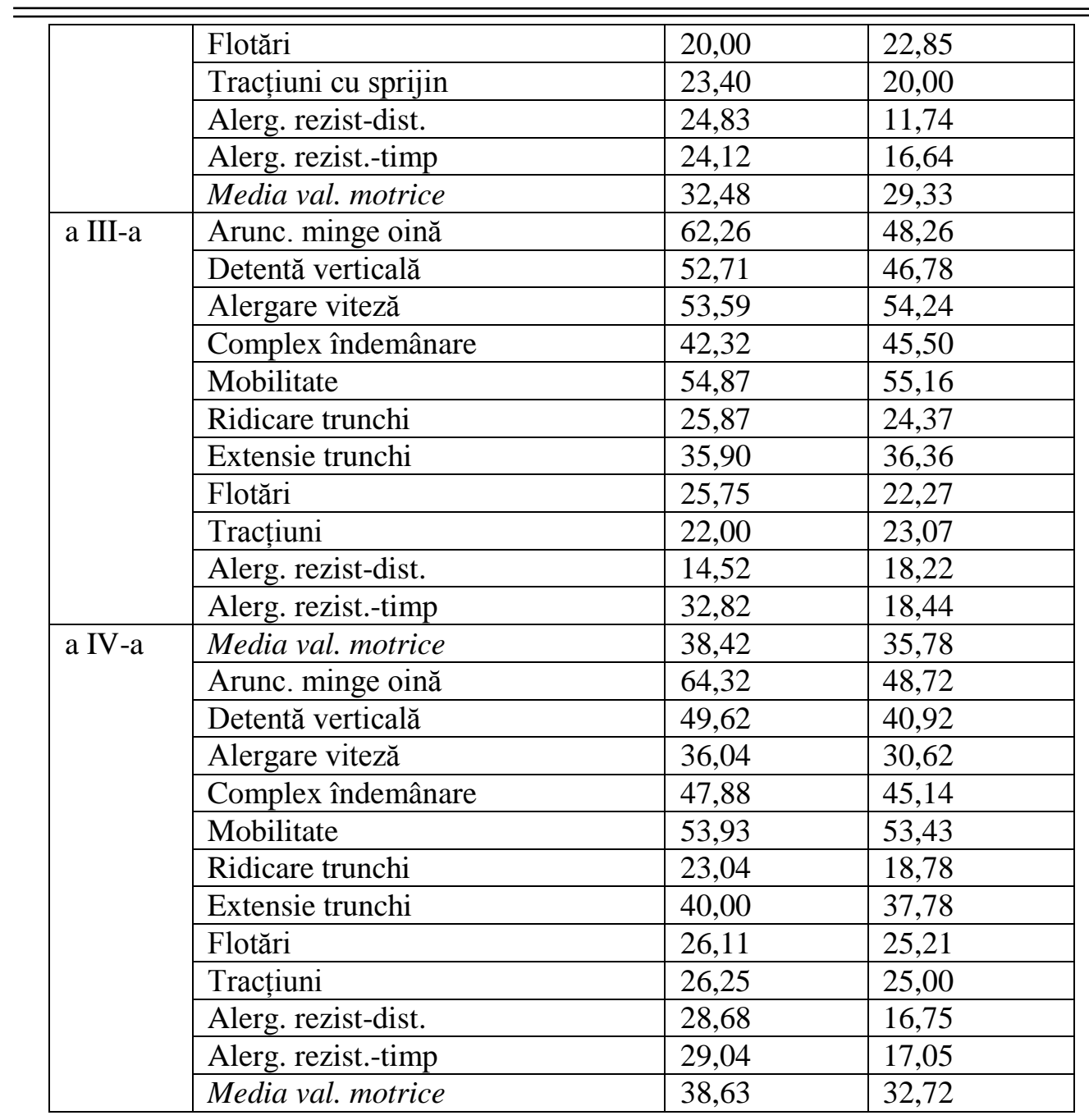

Înregistrarea parametrilor și calcularea mijloacelor sunt utile pentru cercetarea deoarece acestea asigură valorile parametrilor psihosomatici care se comparata în timp, ca urmare a cercetărilor periodice. Pentru a fi mai precis, pentru ca reprezentarea să fie mai evidentă, s-a folosit metoda grafică pentru a sublinia partea media a valorii motoare. Mutând analiza în zona psihosomatică (tabelele 1 și 2), se poate vedea că mijloacele raportate la al doilea test sunt mai bune decât primul.

Așa cum era de așteptat, la vârsta de școală primară (6-10 ani), valorile psihosomatice pentru fete sunt mai mici decât pentru băieţi. Trebuie remarcat faptul că mijloacele psihosomatice atât pentru eleve cât și pentru elevi sunt etichetate ca satisfăcătoare și nesatisfăcătoare.

Analiza tabelelor arată că într-o sală de clasă marea majoritatea rezultatelor sunt grupate spre limita inferioară, și doar câteva dintre ele sunt cu totul excepțional, acesta din urmă crescând media clasei. Cu toate acestea, acest 
mijloc nu poate convinge că avem de-a face cu o clasă cu mobilitate bună, dar, de fapt, media a fost crescută de cele câteva performanţe remarcabile.

\section{Concluzii}

1. Perfecționarea capacităţii motrice în pregătirea fizică urmărește îmbunătățirea nivelului de dezvoltare a aptitudinilor psihomotrice la nivelul elevilor din ciclul primar.

2. La baza dezvoltării fizice a elevilor din învăţământul primar al municipiului Bacău, trebuie dezvoltată ideea formării capacității de a petrece în mod util timpul liber și de a se recrea.

3. Prin dezvoltarea fizică se asigură păstrarea și întreținerea stării de sănătate în raport cu folosirea exercițiului în combinație cu factorii naturali de călire (aer, apă, soare), în scopul creșterii potențialului de muncă fizică și intelectuală.

4. Realizarea dezvoltării fizice armonioase printr-o paletă largă de exerciții clasice, preluate din diferite discipline sportive și adaptate cerințelor lecției de educatie fizică la nivelul claselor primare.

5. Receptivitatea la nou și îmbinarea creatoare a mijloacelor și metodelor folosite în dezvoltarea fizică a elevilor din ciclul primar, vor conduce nemijlocit la o bună optimizare a lecției.

6. Pentru învățământul primar, la fiecare dintre capacitățile și competențele evaluate, profesorul sau învățătorul va utiliza variante prevăzute ca probe opționale.

7. În dezvoltarea forței la elevi din ciclul primar, se va folosi circuitul mic sau mediu.

8. Dezvoltarea armonioasă a sistemului locomotor, precum şi a celorlalte sisteme şi aparate ale organismului şi îndeosebi a circulaţiei şi respiraţiei, trebuie să constituie condiţia manifestării multilaterale a capacităţii organismului, a formării şi perfecţionării deprinderilor şi priceperilor motrice, a dezvoltării aptitudinilor psihomotrice la elevii din învățământul primar.

9. Odată cu realizarea indicilor funcționali la sfârşitul învăţământului primar, organizarea procesului instructiv-educativ trebuie să aibă în vedere valorificarea influenţelor exerciţiului fizic în direcţia formării şi dezvoltării însuşirilor şi trăsăturilor personalităţii.

10. Este necesar ca lecţiile de educaţie fizică din învăţământul primar să conţină exerciţii care duc la procesul de perfecţionare a dezvoltării fizice în conformitate cu cerinţele concrete ale programelor. 